[CONTRIBUTIONS FROM THE ANALYTICAL LABORATORIES OF COLUMBIA UNIVERSITY.]

\title{
THE INSOLUBLE CARBOHYDRATES OF WHEAT.
}

\author{
By H. C. SHERMaN.
}

Received February 24, 1897.

CONTENTS.

PART I-DESCRIPTIVE.

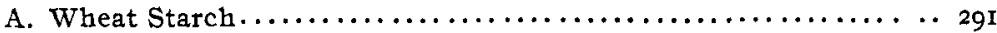

B. Hemicellulose-Pentosans .......................... 292

Preparation and properties of the sample.............. 292

Hydrolysis..................................... 293

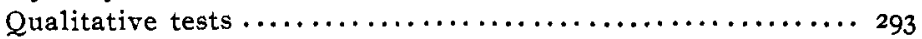

Preparation and analysis of the osazone $\ldots \ldots \ldots \ldots \ldots \ldots \ldots .293$

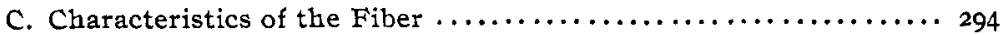

Composition and color reactions ..................... 294

Reactions with ferric chloride and potassium ferricyanide.... 295

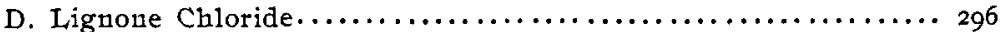

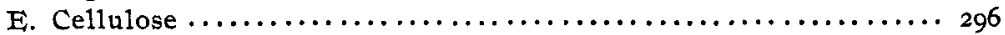

Study of methods of separation $\ldots \ldots \ldots \ldots \ldots \ldots \ldots \ldots \ldots \ldots 296$

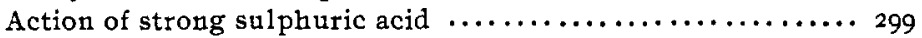

Action of dilute sodium hydroxide................... 299

Chemical nature of the cellulose $\ldots \ldots \ldots \ldots \ldots \ldots \ldots \ldots \ldots \ldots, 300$

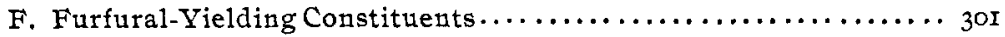

PART II-ANALYTICAL.

A. Separation of the Insoluble Carbohydrates $\ldots \ldots \ldots \ldots \ldots \ldots \ldots \ldots 302$

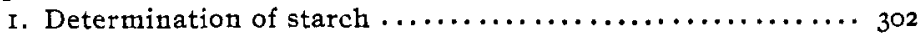

2. Determination of true pentosans.................. 304

3. Determination of cellulose....................... 304

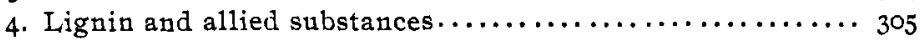

B. Determination of Copper Reduction .................... 305

C. Determination of Furfural $\ldots \ldots \ldots \ldots \ldots \ldots \ldots \ldots \ldots \ldots \ldots \ldots \ldots, 306$

PART III-PHYSIOLOGICAL.

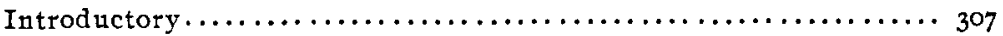

Digestion experiment.............................. 308

Digestibility and physiological value $\ldots \ldots \ldots \ldots \ldots \ldots \ldots \ldots \ldots \ldots, 309$

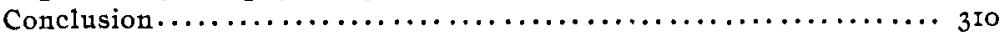

\section{PART I-DESCRIPTIVE.}

A. WHEAT STARCH.

The constitution of wheat starch has been thoroughly investigated by L. Schulze.' A very carefully prepared air-dried starch was employed, allowance being made in the calculations for moisture present in the sample. His results, obtained both by

1 J.prakt. Chem., 535, 3 Ir. 
elementary analysis and by estimation of the dextrose formed on hydrolysis, show conclusively that the formula of wheat starch is $n\left(\mathrm{C}_{6} \mathrm{H}_{10} \mathrm{O}_{5}\right)$ and not, as supposed by Naegeli, $\mathrm{C}_{35} \mathrm{H}_{62} \mathrm{O}_{31}$.

The separation of starch from accompanying carbohydrates has been discussed in another paper and will be referred to in speaking of analytical methods (page 302 ).

\section{B. HEMICELLULOSE-PENTOSANS.}

The term hemicellulose has been introduced by E. Schulze to designate the carbohydrate matter yielded to boiling dilute acids by vegetable cells from which the starch has been removed. It is a portion of the cell-wall rather than of the cell contents." The fact that the hemicellulose of wheat yields both arabinose and xylose on hydrolysis has already been noted. ${ }^{4}$ In general, however, it must be said that the amount of substance which was obtained for identification was so small in proportion to that hydrolyzed as to suggest the question whether the result could be taken as proving the absence of other sugars. I decided to try a method which should not depend upon recrystallization.

Preparation of Sample. - Wheat bran ${ }^{5}$ was extracted successively with water, saline solution, malt extract, two per cent. ammonia, cold two per cent., and boiling one-tenth per cent. sodium hydroxide. Each reagent was removed by thorough washing with water before the application of the succeeding one. This treatment removed, beside fatty and resinous matter, all of the soluble carbohydrates and starch and nearly all of the proteid matter without the use of any acid. The residue consists essentially of cell-walls. ${ }^{6}$

The residue from the extraction with ammonia contained, in the air-dried state, 8.30 per cent. moisture, 8.50 per cent. proteids (nitrogen $\times 6.25$ ), and 3.69 per cent. ash. It yielded, on the basis of non-nitrogenous ash-free substance, 27.62 per cent. furfural (determined as described in Part II) equivalent to 50.82 per cent. pentosans.

1 School of Mines Quarterly, 17, 356 .

2 Ztschr. phys. Chem, i6, 387-39r.

${ }^{3}$ Prcf. C. Cramer, in connection with Schulze's work.

4 Stotie: Ann. Chem. (Liebig), 249, 239: Steiger and Schulze: Ber. d. Chem. Ges., 23, 3Ito; E. Schulze: Ztschr. phys. Chem., I6, 397 .

5 Bran was used instead of the whole grain because it contains all the insoluble carbohydrates of the latter and does not require the removal of so much starch.

o Cramer : Loc. cit. 
The sodium hydroxide extract contained pentosans, giving the characteristic red coloration with phloroglucin in hydrochloric acid and yielding furfural when distilled with hydrochloric acid.

The air-drid residue contained 7.65 per cent. moisture, 1.25 per cent. proteids, and $3.3 \mathrm{I}$ per cent. ash. On the basis of nonnitrogenous, ash-free substance, it yielded 25.62 per cent. furfural equivalent to 48.13 per cent. pentosans.

Hydrolysis of the Hemicellulose. - As it was necessary to choose a somewhat arbitrary treatment, I adopted that which forms a part of the ordinary method of food analysis ; viz, thirty minutes boiling with I.25 per cent. sulphuric acid. About one-half of the substance dissolved. The residue was washed free from acid and preserved for further examination.

To the solution sufficient sulphuric acid was added to bring the total present to two per cent., and it was then boiled gently with a reflux condenser until the reducing power of the solution no longer increased (six hours). This reducing power was found to be equivalent to $9 \mathrm{I} .2$ per cent. of that of dextrose and showed that the solids in solution consisted almost entirely of reducing sugars. A second determination showed the organic solids in solution to have a reducing power of $9 \mathrm{r} .3$ per cent. of that of dextrose.

Qualitative Tests.-The solution was tested ${ }^{1}$ for mannose with phenylhydrazine acetate, for galactose by evaporation with nitric acid, and for levulose by resorcin in hydrochloric acid. All of these tests gave negative results. Reactions of the pentoses indicated their presence in larger proportion. No direct test for dextrose, applicable under these circumstances being known, the osazone was next prepared.

Preparation of the Osazone.-This was carried out essentially as described by Gans and Tollens. ${ }^{2}$ A part of the solution was concentrated on the water-bath until it contained ten per cent. of solids, cooled to $70^{\circ}$, and then mixed with an equal volume of a solution containing for each gram of carbohydrate treated, two grams phenylhydrazine hydrochloride and three grams of sodium acetate. The mixture was kept at $65^{\circ}-70^{\circ}$ for about forty-five minutes and then allowed to cool. The osazone separated as a

1 Lippmann : Chemie der Zuckerarten, 338,395 , and 483.

2 Ann. Chem. (Liebig), 149, 249. 
yellow iridescent precipitate which was collected, washed thoroughly and dried without recrystallization. Thus it was hoped to secure a product nearly representative of the entire solution, and whose composition should show the relative proportions of pentose and hexose present. As the yield of osazone is never quantitative, this method cannot be regarded as absolutely accurate, but, on the other hand, both dextrose and the pentoses form their osazones easily and freely under the conditions described.

Since Stone ${ }^{1}$ has found that the osazones of the pentoses are soluble in about fifty parts of water on continued boiling, while glucosazone is quite insoluble, the proportion of the latter, if any were present, could be largely increased by dissolving away most of the pentose compound. Accordingly a part of the osazone described above was boiled for ten minutes with about forty parts water, whereby about three-fourths was dissolved. The residue was dried and analyzed as was the original preparation.

Analysis of the Osazones. - The percentage of nitrogen in each of the preparations was determined by Dumas' method with the following results :

First Preparation. - Original precipitate; a. 0.1716 gram yielded $26.6 \mathrm{cc}$. nitrogen at $29.5^{\circ}$ and $764.4 \mathrm{~mm}$. pressure.

b. 0.1694 gram yielded $25.8 \mathrm{cc}$. nitrogen at $20.0^{\circ}$ and 759.4 mm. pressure.

Second Preparation.-Residue; 0.0993 gram yielded I4.8 cc. nitrogen at $21.0^{\circ}$ and $76 \mathrm{r} .0 \mathrm{~mm}$. pressure.

From which we obtain :

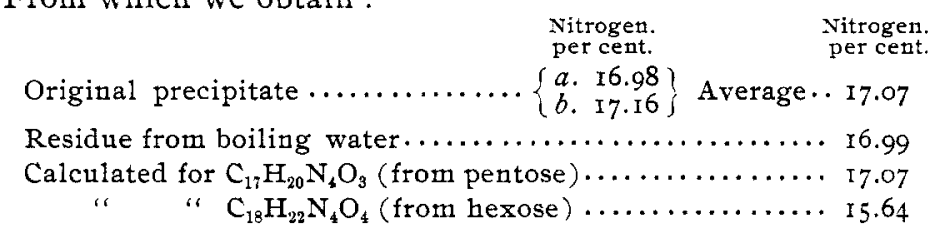

The hemicellulose of wheat appears then to yield on inversion only pentoses and, therefore, to consist of pentose anhydrides or true pentosans.

$$
\text { c. CHARACTERISTICS OF THE FIBER. }
$$

Composition and Color Reactions. - The residue from the action of sulphuric acid, after washing with water and alcohol and dry-

1 Am. Chem.J., 15,662. 
ing in the air, was of a medium brown color and loose fibrous texture. It contained 3.43 per cent. moisture, 0.65 per cent. ash, 0.25 per cent. nitrogen, and yielded I I.46 per cent. furfural. It showed well the deep magenta color (produced by lignin) when treated with chlorine and then boiled with sodium sulphite, and gave the red coloration when heated with the phloroglucin reagent (test for pentosans). No coloration was obtained on treating the fiber with a solution of fuchsin decolorized with sulphurous acid nor on boiling with anilin sulphate (tests for oxycellulose).

Reactions with Ferric Chloride and Potassium Ferricyanide.Jute fiber, when immersed in a solution containing molecular proportions of the above reagents, fixes upon itself a large proportion of ferrous ferricyanide as a uniform deep-blue dye. This is considered by Cross and Bevan ${ }^{1}$ as one of the most characteristic reactions of the lignocelluloses of which jute is the type.

In my experiments on the wheat fiber, I used a fresh mixture of equal volumes of aqueous solutions çontaining in roo cc., one and six-tenths grams ferric chloride and three and three-tenths grams potassium ferricyanide respectively. The increase in weight of the fiber after immersion in this solution was determined by collecting in a Gooch crucible, washing well with cold water, and drying at $105^{\circ}$. The following quantitative experiments were made:

\begin{tabular}{|c|c|c|c|}
\hline \multicolumn{2}{|c|}{ SERIES A.-TIME VARIED. } & \multicolumn{2}{|c|}{ Masses Constan'T. } \\
\hline $\begin{array}{l}\text { Weight of } \\
\text { fiber. }\end{array}$ & $\begin{array}{l}\text { Volume of mixed } \\
\text { solution. }\end{array}$ & $\begin{array}{l}\text { Time of im- } \\
\text { mersion. }\end{array}$ & $\begin{array}{l}\text { Increase in } \\
\text { weight. }\end{array}$ \\
\hline Gram. & cc. & & Per cent. \\
\hline 1.00 & 20 & 20 min. & 9.40 \\
\hline I.0O & 20 & I hour & II.I7 \\
\hline 1.00 & 20 & Io hours & II.I 6 \\
\hline
\end{tabular}

With these proportions, then, the reaction proceeds rapidly to the maximum.

Series B.-Time Varied. Masses Constant.

$\begin{array}{cccc}\begin{array}{c}\text { Weight of } \\ \text { fbet. }\end{array} & \begin{array}{c}\text { Volume of mixed } \\ \text { solution. }\end{array} & \begin{array}{c}\text { Time of im. } \\ \text { mersion. }\end{array} & \begin{array}{c}\text { Increase in } \\ \text { weight. }\end{array} \\ \text { Gram. } & \text { cc. } & \text { Hours. } & \text { Per cent. } \\ 1.00 & 20 & \text { I6 } & \text { II.26 } \\ 1.00 & 40 & 16 & 21.8 \mathrm{I} \\ 1.00 & 60 & 16 & 30.49 \\ 1.00 & 80 & 16 & 36.7 \mathrm{r} \\ 1.00 & 100 & 16 & 46.70\end{array}$

1 cellulose, p. I24-I31. 
Wheat fiber has, therefore, like the typical lignocellulose (jute), the power of fixing upon itself an amount of the cyanide varying roughly with the amount exposed to its action. This reaction is very interesting as showing the similarity of the lignocellulose molecule in these tissues. It will be shown to be of value also as a test of the purity of cellulose.

D. LIGNONE CHLORIDE.

Cross and Bevan ${ }^{1}$ have isolated a compound from chlorinated jute fiber to which they give the above name. Its composition corresponds to the formula $\mathrm{C}_{19} \mathrm{H}_{18} \mathrm{C}_{14} \mathrm{O}_{9}$ and is constant after fractional precipitation and when prepared under varying circumstances. It is precipitated as yellow flocks when its alcoholic solution is diluted with water.

Seventy-five grams of the fiber already described was boiled with one per cent. sodium hydroxide, washed, pressed to remove most of the water, treated with chlorine gas for one hour, washed free from hydrochloric acid, and covered with alcohol. On pressing out the alcoholic solution it was found to be of a deep golden yellow color. On concentrating and pouring into water a part only of the dissolved substance separated, as was shown by the color of the supernatant liquid. The precipitate obtained, although small (about one-half gram), corresponded in appearance with that described and on collection and analysis showed 26.7 per cent. chlorine, or just the amount required by the above formula. This seems sufficient evidence of the identity of the products.

I do not know that this compound has previously been prepared from any other source than commercial fibers, but the fact that it may be obtained from such a widely different tissue as that of the coat of the wheat kernel would indicate that this type of lignification may be general among plants of annual growth.

On the other hand, the amount recovered is too small to justify much speculation until further results are obtained.

E. CELLULOSE.

For the separation of cellulose three very different methods were tried.

I. F. Schulze's Method.-Thirty grams of the fiber was treated

1 Cellulose, p. 135 . 
at ordinary temperature with a solution of twenty-five grams potassium chlorate in $350 \mathrm{cc}$. of nitric acid (I.IO sp.gr.). After standing seven days with occasional stirring, the strength of nitric acid was raised to I.I $3 \mathrm{sp}$. gr. by the addition of concentrated acid, and the digestion continued for another seven days. Finally, the mixture was kept at about $40^{\circ}$ for two hours, then filtered, washed free from acid, and treated on the filter with cold two per cent: ammonia as long as the filtrate was colored, and the washing finished with water and alcohol.

The sample seemed particularly resistant to this treatment so far as appearance was concerned. Instead of becoming white, it attained during the first two or three days a dull flesh color which was not materially changed during the remainder of the fortnight. The color of the dried residue was light brown, very much lighter than, but still suggesting, that of the original fiber. By repeating the treatment or increasing its severity a purer residue could doubtless be obtained but, as the yield is already less than that from the method next to be described, there seems no object in experimenting in this direction.

The residue constituted 66.0 per cent. of the original. It yielded 7.00 per cent. furfural and gave the red coloration when heated with phloroglucin. When boiled with anilin chloride it was tinged very faintly reddish, indicating a trace of oxycellulose. From twenty parts of the standard cyanide solution it absorbed 6.04 per cent. of its weight of the pigment, indicating, as comparison with the other cellulose will show, that the lignin group was not selectively attacked.

2. Method of Cross and Bevan.-Thirty grams fiber was boiled thirty minutes with $800 \mathrm{cc}$. of one per cent. sodium hydroxide, filtered, washed with water till free from alkali, squeezed as free from the water as possible, and then exposed in this moist condition to the action of chlorine gas in a covered beaker at ordinary temperature for one hour with occasional stirring. The color changed rapidly from brown to light lemon-yellow. At the end of the hour it was brought upon a filter and washed with water till free acid was removed, then heated to boiling with $600 \mathrm{cc}$. of two per cent. sodium sulphite and sufficient sodium hydroxide solution added to make two-tenths per cent. of the whole. The boiling was continued five minutes, the solu- 
tion filtered hot and the residue washed until the washings were neutral and colorless. It is convenient to use a muslin filter and hasten the operation by squeezing out the washings. Finally the washing was finished with alcohol and the residue dried and weighed.

This process yielded 66.5 per cent. of residue of a light creamy color and free from nitrogen. It yielded 5.62 per cent. of furfural and gave a distinct coloration with phloroglucin, but not with anilin chloride. From the cyanide solution it absorbed only 0.92 per cent.

3. Lange's Method of Fusion with Alkali.-Bring five to ten grams of the (fat-free) substance into a porcelain crucible about three inches high with three times as much caustic potash and about twenty cc. of water. Heat with stirring in an oil-bath not above $180^{\circ}$, keep at this temperature $\left(175^{\circ}-180^{\circ}\right)$ for an hour, cool to $75^{\circ}-80^{\circ}$, add about seventy-five cc. hot water, cool, acidulate with sulphuric acid, make slightly alkaline with sodium hydroxide, and separate the precipitate by means of a centrifugal machine. The liquid is poured off and the cellulose washed with hot water, separating in the same way. Bring onto a filter; wash with water, alcohol and ether, dry and weigh. Incinerate and deduct the ash. ${ }^{1}$

Ten grams were used for each determination; the melting proceeded quietly and without troublesome frothing. The precipitate was allowed to settle by standing instead of separating by centrifugal force. Thus obtained it was of a somewhat slimy character, and the process of filtering and washing is therefore slow. This is the only difficulty of manipulation which the method presents. The cellulose dried to a white powder, the fibrous nature having been destroyed by the treatment.

Lange obtained higher results by this method than by that of Schulze, but in this case I recovered only 39.3 to 43. I per cent. cellulose (without allowing for ash). The product yielded 3.96 per cent. furfural and gave the phloroglucin reaction, although not so markedly as did the other preparations of cellulose. Boiled with a solution of anilin salt it showed no evidence of any oxycellulose. From the cyanide solution it absorbed 0.89 per cent.

1 Ztschr. angew. Chem., $2895,56 \mathrm{I}$. 
Choice of Method of Preparation.-For reasons which are mainly obvious, but which will be reviewed in speaking of analytical methods, the process of separation by means of chlorination is preferred, and cellulose thus obtained was employed in the following experiments.

Action of Strong Sulphuric Acid.-Strong sulphuric acid (I0O parts sulphuric acid and seventeen parts water) dissolves pure cotton cellulose with only very slight coloration and the solution when diluted and boiled yields dextrose. E. Schulze ${ }^{1}$ has found the same to take place with cellulose residues from other natural tissues prepared by vigorous acid hydrolysis followed by F. Schulze's reagent, although the amounts of dextrose obtained were small.

When applied to the cellulose described above, under the conditions given by Schulze, the solution was not complete and a very considerable discoloration was produced. The undissolved portion (nearly one-fifth) did not yield a measureable amount of furfural. The final product of hydrolysis of ten grams of the cellulose, converted into osazone in the usual way, gave only I.3 I grams of the latter. Its composition is shown by the following results :

a. O. I9I4 gram gave $25.9 \mathrm{cc}$. nitrogen at $23.8^{\circ}$ and $775.5 \mathrm{~mm}$. pressure, equal to 15.48 per cent. ; $b$. O. I 870 gram gave $24.7 \mathrm{cc}$. nitrogen at $17.0^{\circ}$ and $771.0 \mathrm{~mm}$. pressure, equal to $15.5^{8}$ per cent.; average $\mathrm{I}_{5} .53$ per cent. ; calculated for $\mathrm{C}_{18} \mathrm{H}_{22} \mathrm{~N}_{4} \mathrm{O}_{4}$ I 5.64 per cent.

The osazone is, therefore, that of dextrose and the specific products of hydrolysis of the furfural-yielding group do not appear.

Action of Cold Dilute Sodium Hydroxide.-Twenty grams cellulose was treated with $400 \mathrm{cc}$. five per cent. sodium hydroxide at room temperature with occasional stirring for two days, filtered and washed. The filtrate was light brown in color, and on neutralizing with hydrochloric acid a white precipitate was formed. I was not able to separate this precipitate quantitatively, but enough was collected to show its general resemblance to wood gum, and it gave the characteristic deep red coloration with phloroglucin. The residue constituted about eighty per

\footnotetext{
1 Ztschr.phys. Chem., I6, 414.
} 
cent. of the amount treated. It was whiter than before treatment. A determination of furfural gave 3.34 per cent., equal to 2.67 per cent. of the original. Hence less than one-third of the dissolved substance was pentosan, and the suggestion of Hoffmeister ${ }^{1}$ that this treatment be inserted as a step in the determination of cellulose, would seem of no value.

Chemical Nature of the Cellulose.-The term cellulose is here used in an inclusive sense to designate the strictly carbohydrate radicle as opposed to the more or less "condensed" lignin substance with which it is combined in the lignocellulose. The abnormal characteristics of this sample (property of yielding furfural and coloring phoroglucin reagent) I believe to be due to the inherent nature of the cellulose itself rather than to imperfect methods for its separation, except in the case of Schulze's method. The sample contains about ten per cent. of penta-anhydride which appears to be chemically combined with a part at least of the hexa-anhydrides (normal cellulose). It may be well now to review some of the reasons for this belief.

I. The absence of lignin groups is strongly indicated $(a)$ by the fact that the repetition of the chlorination followed by treatment with sodium sulphite gave no red coloration, and very slight loss of weight, $(b)$ the insignificant amount of cyanide absorbed (less than one per cent.)

2. The method of fusion with alkali, totally different in its nature, causing complete disintegration of the fiber and a much lower yield than the chlorination method, still produces a cellulose in which the abnormal characters differ only in degree from those shown by the product of the latter process.

3. The imperfect solubility in sulphuric acid and the small amount of glucosazone formed from the product of hydrolysis indicate that the cellulose is not of the normal type.

4. The proportions of substances extracted by dilute alkali show that the sample is not a simple mixture of pentosan and normal cellulose.

5. Somewhat similar characters have been found by others ${ }^{2}$ in studying natural celluloses prepared by other methods than

1 Lanaie. Versuch-sta., 39, 46r.

2 C. Schulze and Tollens : Landw. Versuch-sta., 40, 367; Hoffmeister: Landw. Versuchsta., 39. 46I: Winterstein: Ztschr,phys. Chem., 17.39I; E. Schulze: Ztschr. phys. Chem., I6, 4I4. 
those (Cross's and Lange's methods) to whose products the above statements refer.

\section{F. FURFURAL-YIELDING CONSTITUENTS.}

Some of the facts observed in connection with this class of bodies would seem worthy of mention here. They constitute nearly or quite one-half of the seed-coat exclusive of starch and proteids-a much higher proportion than is found in woods, straws, or commercial fibers-and by far the greater part is in the form of easily hydrolyzed pentosans. The physical effect of these in rendering the tissue more tenacious and more retentive of moisture is doubtless of considerable physiological significance. It was observed in the course of this work that the samples which had not been treated with acid held about twice as much hygroscopic moisture as did those from which the pentosans had been removed, when similarly air-dried. In the case of isolated xylan, this affinity for moisture is so great as to be a most serious obstacle to its analysis.'

The wide distribution of furfural-yielding bodies among the different chemical groups which compose the cell-wall has been shown by the quantitative determinations mentioned above, in the original tissue, in the fiber remaining from acid treatment, in the cellulose isolated from the latter by various methods, and in cellulose which had been further treated with dilute sodium hydroxide. We have also seen that all of these specimens gave distinct pentosan reactions ${ }^{2}$ with phloroglucin and that none of them gave distinct oxycellulose reactions with anilin salts. We therefore conclude that the furfural-yielding constituents of wheat are essentially pentosans in some form and that we commit no serious error in interpreting the amount of furfural obtained as a measure of the total pentosans present. But if we should use the term pentosans in this exclusive sense and stop here, it would be little more satisfactory than to include dextrin, starch, and cellulose in one group of hexosans. Our pentosans would con-

1 Johnson: This Journal, 18, 214.

2 Note.-While the work was in progress the results of Cross and Bevan on the furfuroids of straws appeared $(J$. Chem. Soc., 69, 804-8I 8$)$. In view of the purple reactions with phloroglucin found by them, it was thought best to retest all the celluloses side by side with a pentose solution. Especially in the cases where the reaction was least marked, the color appeared somewhat darker and not so clear as in the pentose solution, but the difference seems to be due to the degree of heat used to develop the color. When the phloroglucin compound was precipitated by boiling and then dissolved in alcohol, no such differences were found in the alcoholic solutions. 
stitute practically all of the hemicellulose, about forty per cent. of the lignin group or non-cellulose of the fiber, and about ten per cent. of the cellulose (chlorination method). It would seem much better, therefore, to distinguish between those pentosans which are easily dissolved by dilute acids without materially affecting the cellulose or lignin, and those which on the other hand, are resistant to acid, or to both acid and alkaline, hydrolysis. The former are evidently not combined with hexose groups and they may be considered as true or free pentosans; the latter are apparently in chemical combination, partly in the lignin group and partly in the cellulose.

\section{PART II-ANALYTICAL.}

A. SFPARATION OF THE INSOLUBLE CARBOHYDRATES.

It is customary in cereal analysis either to be content with the results of the Weende method or to determine in addition the starch and perhaps also the furfural obtainable and calculate the latter to pentosan. The latter determination we have seen to be to a certain extent misleading since a part of the furfural comes from bodies in combination both in the cellulose and in the lignin groups and while apparently of a pentose nature, these are quite different in their properties from the true pentosans of the hemicellulose. In order to separate quantitatively the carbohydrates described in the first part of this paper, it is necessary to combine the methods best adapted to the determination of each into a single scheme. So much time was required to test the different methods and the products yielded by them that some of the details are in need of further study and the results are offered as approximate rather than absolute or final. An outline of the scheme is given and is followed by a discussion of the different steps. An application of the scheme is found in Part III.

I. Determination of Starch.-The results of a comparison of several methods on a series of samples specially selected to show gradations in the amount of starch present, has been published in the School of Mines Quarterly, ${ }^{1}$ and abstracted in the Analyst for January, 1897 . These results show the superiority of the malt extract method and the safety of completing the inversion of the solutions with hydrochloric acid by boiling as suggested by Hibbard," instead of by long heating on the water-bath. 
INSOLUBLE CARBOHYDRATES OF WHEAT.

303

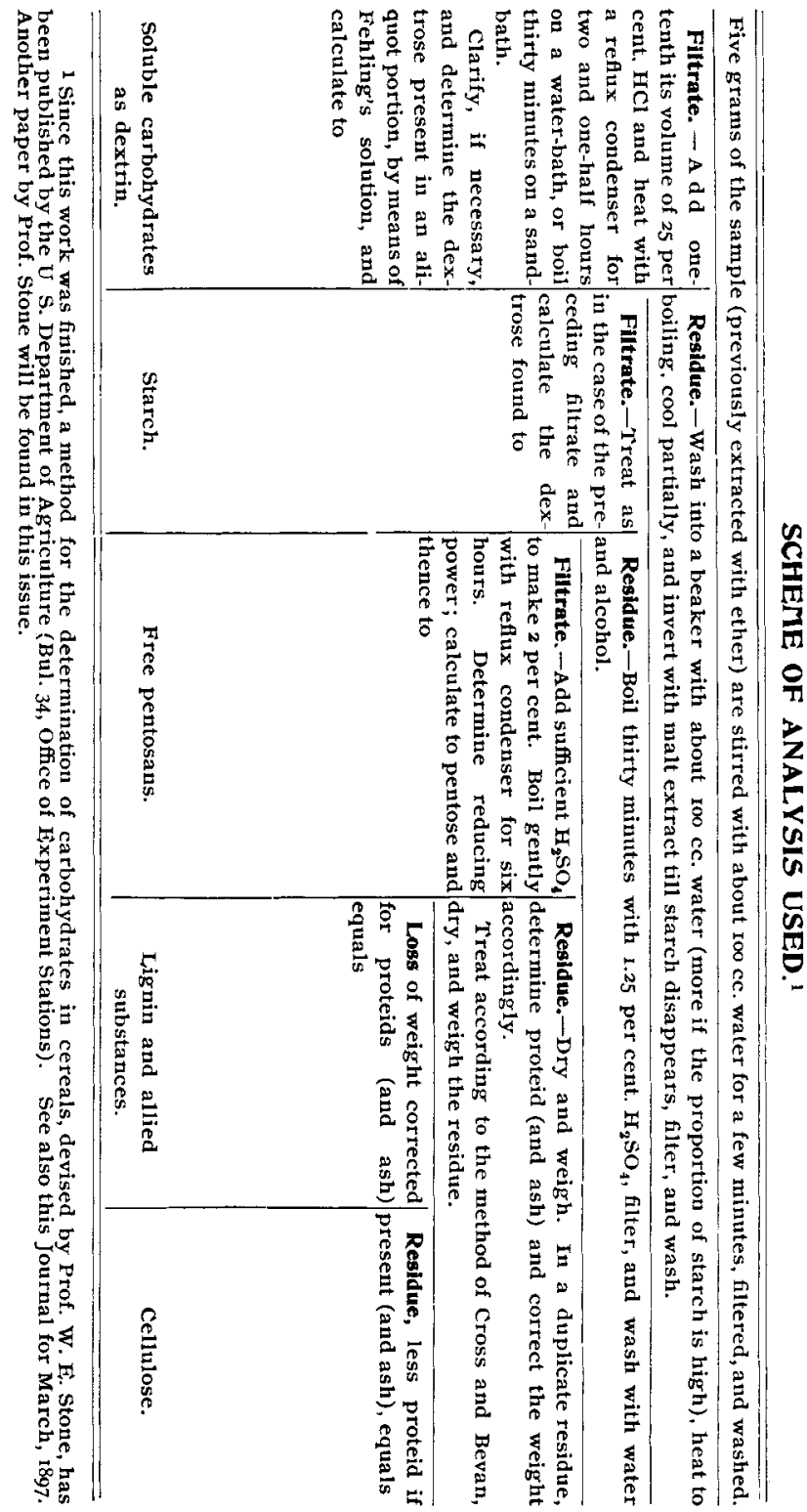


2. The Determination of True Pentosans.-Reference has been made to the interpretation of furfural as a measure of pentosans (p. 302). It has been shown that by hydrolysis of the hemicellulose solution, pentoses only are obtained. Since, moreover, isolated pentosans are readily dissolved by dilute acids, it is evident that hydrolysis of this solution and determination of the pentosans formed must give a fairly accurate measure of the true pentosans. The kind and strength of acid used should be a subject for further stucly. Sulphuric acid was used in this work because the pentoses are so little altered by long boiling with it.' The reducing power was referred to dextrose by Allihn's table and the pentose taken as ninety-seven per cent." of the amount of dextrose indicated. Pentose $\times 0.88=$ pentosan.

3. The Determination of Cellulose. - The three methods compared have been described above (pp. 296, 297, 298). Exposing to chlorine after simple wetting without alkaline treatment, and then proceeding as in the chlorination method has been tried and the results are tabulated with those obtained by the regular methods. The fiber itself is also shown for purposes of comparison.

\begin{tabular}{|c|c|c|c|c|}
\hline Metho & $\begin{array}{l}\text { Yield } \\
\text { per cent }\end{array}$ & $\begin{array}{l}\text { Des } \\
\text { Furfural } \\
\text { percent. }\end{array}$ & $\begin{array}{l}\text { Ijption of } \\
\text { Nitrogen } \\
\text { percent }\end{array}$ & $\begin{array}{l}\text { Product. } \\
\text { Ferricyanide } \\
\text { fixed; per cent. Color. }\end{array}$ \\
\hline Cross and Bevan ...... & 66.5 & 5.62 & 0.00 & 0.92 Light cream. \\
\hline Lange $\ldots \ldots \ldots \ldots \ldots$ & - $4 \mathrm{I} .2$ & 3.96 & 0.03 & 0.89 Nearly white. \\
\hline Schulze............ & . 66.0 & 7.00 & $0.22^{3}$ & 6.04 Light brown. \\
\hline Chlorination alone... & $\cdot 84 \cdot 3$ & 8.89 & 0.08 & 2.02 Very light brown. \\
\hline 1 saingie. & & 46 & 0.25 & \\
\hline
\end{tabular}

It is evident that no one feature can be urged as a criterion in judging between the methods but all must be taken into consideration. Such a comparison shows the superiority of the chlorination method. It also suggests the possibility of increasing the yield without detriment to the quality of the product, by making the preceding alkali treatment less severe.

The reaction with the ferricyanide solution ( $p .295$ ) seems of considerable value in testing the purity of celluloses. When the sample increases only slightly (about one per cent. or less) in

1 Tollens and Schulze : Landw. Versuch-sta, , 40, 379-384.

2 Stone: Am. Chem.J.. 13, 73.

3 Exclusive of 0.07 per cent. ammoniacal nitrogen (fro't the wash solution) determined by distillation with magnesia. 
weight and is dyed only a bluish-green instead of a deep blue color, it is at least a very strong indication that lignin substances are not present in notable quantity. When the original fiber is dark-colored, the appearance of the cellulose will also serve as a guide, for unless this color has disappeared, it is probable that the lignin group has not been completely removed.

The significance of the furfural-yielding property of these celluloses has been discussed in the first part of this paper.

4. Lignin and Allied Substances. - These are determined by loss of weight when cellulose is isolated from the fiber. The general characteristic feature of the substances is their susceptibility to alkali. This is the principle upon which Lange's method is based; but since the treatment called for by the latter evidently attacks the cellulose, it is best to remove the more readily soluble portion by boiling with dilute alkali and then treat with chlorine to convert the remainder into a more easily soluble compound. The first step is also introduced in the current analytical methods, and the term lignin is usually restricted to the portion which remains with the cellulose in the "crude fiber." There is, however, no established chemical difference on which to rest such a distinction, and it is, therefore, omitted here, although the step might easily be introduced if desired.

\section{B. DETERMINATION OF COPPER REDUCTION.}

Wherever in this paper, the reducing power of a solution is given, the determination has been made by adding twenty-five cc. of the solution to be tested to an excess of boiling Fehling's solution under the usual conditions of dilution, boiling exactly two minutes, collecting and estimating the cuprous oxide and taking the corresponding value for dextrose from Allihn's table. In most cases the cuprous oxide was determined as follows: ${ }^{1}$ Collect the reduced oxide on asbestos in a filtering tube and wash well with water. Dissolve on the filter with nitric acid and wash thoroughly into a flask. To the solution add excess of sodium carbonate and dissolve the precipitate with one cc. of ammonia $(0.96 \mathrm{sp} . \mathrm{gr}$.). Titrate with a recently standardized solution of potassium cyanide until the color disappears.

The method is rapid and accurate since no other heavy metals than copper can be present. Before adopting it I checked it

1 Lavene: School of Mines Quarterly, 17. No. 4. 
against the electrolytic method and made a large number of experiments to show that varying amounts of sodium nitrate had no effect upon the result. After a little practice in determining the end reaction, I believe the results obtained should be as accurate as by the gravimetric methods, and much more accurate than simple titration with Fehling's solution.

\section{DETERMINATION OF FURFURAI.}

The method used was essentially that of the Association of Official Agricultural Chemists, but as that may not be available to all, and as some of the details were modified, it is given in full.

From two to five grams of the sample are placed in a flask with IOO cc. of hydrochloric acid of 1.06 specific gravity. The mixture is distilled and the distillate collected in a graduated receiver. Each thirty cc. lost by distillation (which should require from ten to fifteen ininutes), is replaced by thirty cc. of hydrochloric acid of the strength mentioned above. Continue the process until a drop of the distillate produces no red coloration in a slip of filter paper moistened with anilin acetate. Eight to twelve distillations are usually required. Add to the distillate sufficient water to bring to a volume of $400 \mathrm{cc}$. and for every fifty cc. of water added, add 10.2 grams sodium chloride. Neutralize exactly with sodium carbonate, and add ten cc. of a solution of phenylhydrazine acetate, made by mixing twelve grams phenylhydrazine with seven and five-tenths grams glacial acetic acid and diluting to $100 \mathrm{cc}$. Stir thirty minutes and let stand in a dark closet until the following day. Filter on glass wool in glass filtering tubes six to seven inches long, removing the precipitate which adheres to the beaker by means of a feather. Dry to constant weight in an air-bath at $55^{\circ}$ to $60^{\circ}$ in a slow current of dry air. A partial vacuum is produced in the tube by means of suction, the supply of air being regulated by stop-cocks. Finally the precipitate is dissolved by hot alcohol, the tube dried and weighed and the loss of weight calculated as furfural hydrazone. For reducing to furfural and to pentosans the following formulas were used:

$$
\begin{aligned}
& \text { Hydrazone } \times 0.516+0.0104=\text { furfural, } \\
& \text { Furfural } \times \mathrm{x} .84=\text { pentosans, }
\end{aligned}
$$


the factor for pentosans is obtained by averaging those of xylan and araban.

The following results obtained after only a very few preliminary trials, show what agreement may be expected without much practice.

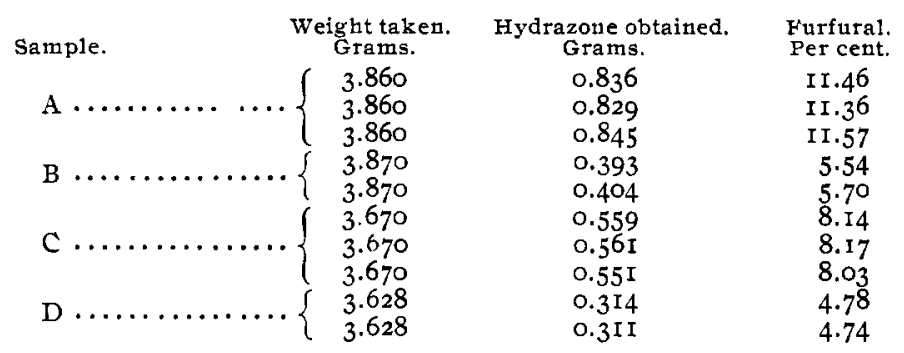

PART III. PHYSIOLOGICAL.

INTRODUCTORY.

In questions of nutrition the proportion of food and of each of its proximate ingredients which is digested, $i . e$. , which leaves the alimentary canal and enters the physiological interior of the body, is evidently the basis of all further studies. While the different substances digested are not all utilized to the same extent, and while the undigested residue undoubtedly performs an important physiological function, these facts only serve to show the necessity of further study based upon the "digestive coefficients" and do not detract from the value of the latter when properly interpreted. Such digestive coefficients to be comparable must of course be determined by uniform methods. The analytical method used by the experiment stations in this country is published by the U.S. Department of Agriculture.' The work of these stations, as well as important foreign work, is periodically reviewed in the Experiment Station Record." A yearly digest of the subject is included in the Jahresbericht für Agricultur-chemie, and it has been treated by Dietrich and Konig. ${ }^{3}$

It is mainly upon these experiments with animals that we are obliged to base our estimates of the digestibility of wheat and wheat products since the published results of experiments with

1 Bul. 46, Division of Chemistry.

2 Published by the U.S. Department of Agriculture.

3 Zusammensetzung und Verandlichkeit der Futtermitte1. 
men $^{1}$ are very incomplete. But the results obtained by current methods of analysis give little information regarding the carbohydrates, this group being simply divided by an arbitrary line (sometimes considered a rough imitation of the digestive process, into " nitrogen-free extract" and " crude fiber."

Recently a number of determinations of digestibilities of total furfural-yielding substance have been reported, especially by Stone $^{2}$ and Lindsey. ${ }^{3}$ Those of wheat bran fed to different animals (sheep and rabbits) and at different times vary from fiftynine to sixty-four per cent.

\section{DIGESTION EXPERIMENT.}

Having studied the chemical nature of the principal carbohydrates of wheat it is interesting to find the digestibility of each as determined by an actual experiment. I was fortunate in obtaining, through the kindness of Mr. H. J. Patterson, of the Maryland Experiment Station, samples of the food and feces from an experiment conducted by him upon a steer fed with wheat bran only. The total dry matter digested was 68.33 per cent. of the whole. The samples were analyzed by the method outlined above, the small amount of ash in the cellulose being neglected. The results, calculated to the dry basis, are as follows :

\begin{tabular}{|c|c|c|c|}
\hline & $\begin{array}{c}\text { Food. } \\
\text { Per cent. }\end{array}$ & $\begin{array}{l}\text { Feces. } \\
\text { Per cent. }\end{array}$ & $\begin{array}{l}\text { Per cent. } \\
\text { Digested. }\end{array}$ \\
\hline Soluble carbohydrates as dextrin & n 7.2 & 0.7 & 96.9 \\
\hline Starch $\ldots \ldots \ldots \ldots \ldots \ldots \ldots \ldots \ldots \ldots$ & $\cdot 17 \cdot 7$ & 0.0 & IOO.O \\
\hline 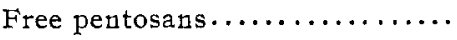 & . 17.5 & I 8.7 & 66.2 \\
\hline Cellulose $\ldots \ldots \ldots \ldots \ldots \ldots \ldots$ & . 8.5 & 20.2 & 24.8 \\
\hline Lignin and allied substances... & - II.6 & 2.3 .2 & 36.7 \\
\hline 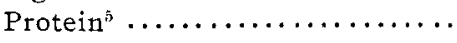 & . 20.49 & II.04 & 82.96 \\
\hline Ether extract ${ }^{5} \ldots \ldots \ldots \ldots \ldots \ldots$ & - 6.92 & I 2.52 & 42.73 \\
\hline $\operatorname{Ash}^{5} \ldots \ldots \ldots \ldots \ldots \ldots \ldots \ldots \ldots \ldots \ldots$ & - 6.05 & II.04 & $42.2 \mathrm{I}$ \\
\hline Undetermined $\ldots \ldots \ldots \ldots \ldots \ldots$ & - 4.04 & 2.60 & $\cdots$ \\
\hline & & $4 x \cdot 93$ & 76.08 \\
\hline Crude fiber ${ }^{\dot{3}}, \ldots \ldots \ldots \ldots \ldots \ldots$ & - 10.96 & 23.47 & $32.2 \mathrm{I}$ \\
\hline
\end{tabular}

We see from the above that the digestibilities of the insoluble 1 Compiled by Atwater : Bul. 2I, Office of Experiment Stations, C.S. Department of Agriculture.

2 Am. Chem.J., 14, 9;Agr. Sci., 5, 6.

3 Mass. Station Report for I894, p. I85-I86.

4 Marylatud Station, Bul, 4r, pp. $137-r_{3} 8$.

5 From Patterson's analysis. 
carbohydrates range from 25 to Ioo per cent. The "nitrogenfree extract" with a mean digestibility of seventy-six per cent. is composed of substances whose percentage digestibilities vary from IoO to less than forty. Even in the case of the crude fiber the digestibility of one of the constituents considerably exceeds that of the other. It must be borne in mind in this connection that the group of lignin and similar substances is divided by the current methods, part being included in the nitrogen-free extract and part in the crude fiber.

DIGESTIBILITY AND PHYSIOLOGICAL VALUE.

The final utilization of the normal carbohydrates absorbed by the healthy animal body is known to be practically complete. With lignin and pentosans or pentoses, the case seems to be different. It is held that the lignin of vegetable tissues supplies directly the benzol radicle of the hippuric acid of the urine of herbiverous animals and is, therefore, but little oxidized in the body.

In the case of pentoses and pentosans whose identification is easy, the experimental methods are more direct, yet the results are very conflicting.

Ebstein ${ }^{2}$ found that either arabinose or xylose given to men in doses of twenty-five grams, quickly appeared in the urine unchanged, and he concluded that these sugars were without nutritive value, or at least nearly so. This result has been largely quoted and its importance perhaps overestimated. Salkowski, ${ }^{3}$ and Cramer, ${ }^{4}$ in numerous independent experiments upon men, rabbits, and fowls, found that these sugars were mainly utilized, only about one-fifth (according to Salkowski) being given off in the urine. In many cases (according to Cramer) it was shown by killing the animals that the feeding of pentoses had caused an increased storage of glycogen in the liver. Finally Fretzel, experimenting upon rabbits with xylose, has concluded that this sugar does not tend, either directly or indirectly, to promote the storage of glycogen.

1 Meissner and Shepard: Untersuchungen über das Entstehen der Hippursäure im thierischen Organismus. Hanover, 1866 . Stutzer: Ber. $a$. chem. Ges, 8, 575. Weiske: Zeit. Biol., 12, 24.

2 Archiv. pathol. Anat., 129, $40 \mathrm{r}$ : Centrbl. med. Wissens., $1892,577$.

3 Centrbl. med. Wissens., $2893,193$.

4 Ztschr. Biol, 19, 484.

5 Archiv. ges. Physiol., 56, 273. 
The advisability of distinguishing between starch and pentosans in food analyses is thus emphasized not only by the difference in their digestibility but also by the possible difference in physiological value of the digested portions.

\section{CONCLUSION.}

The results obtained have been discussed under the different sections. It is unnecessary to repeat them here. I would, however, offer a final word of explanation in regard to the liberty taken with the words "cellulose" and "lignin substance." These are used to designate respectively the carbohydrate, and the more or less "condensed" portions of the fiber. That either is chemically homogeneous is certainly not claimed. It is with considerable hesitation that this work is presented at this time. The amount of undetermined matter is still larger than we should wish, but those who are interested in the subject will be familiar with its difficulties, and the separations which have been made may suggest some improvement on the ordinary " nitrogen-free extract" and "crude fiber" of cereal analyses.

\section{DISCUSSION.}

Dr. Wiley: Mr. President and Gentlemen, I think the paper is one of the greatest practical, as well as theoretical, interest. As one who has been engaged for a long time in the analysis of food products, I think it is a mark of great progress to know that we are getting finally to some definite knowledge of that large class of matters which, because it was not extracted, has always been called extract. It has been rather a matter of humiliation, I think, to agricultural chemists for many years that this term has been used in the way it has been. To designate a large part of cattle and human food as nitrogen-free extract is simply to do as doctors do when they say you are suffering from malaria or grippe. It is simply using words which have not much signification, to cover up a great deal of ignorance. It is gratifying that we are now making progress in this particular line. The work in this country which has been conducted by Mr. Sherman and others, and in England by Cross and Bevan, and in Germany by Tollens and his pupils, has all been in the direction of giving us more light on these bodies. The discovery of the fiveatom sugars in cattle foods, and the methods of approximately 
determining them was a great step forward, and the approximate determinations of lignin and cellulose or hemi-cellulose is another step. I think Mr. Sherman should congratulate himself, rather than feel sorry for the fact that he has finally reached a point where all but three or four per cent. of a sample can be distinguished and determined. It may not be that we have yet applied the right names to these bodies. The substances may vary a little from what they seem to be, but evidently they are composed of bodies which can be separated, and their digestibility can be determined. I think we are all, perhaps, struck with the statement given here of the low digestibility of the ether extract. Here is a substance which is just as important, except in the amount of it, as the other constituents of wheat. We have been for years bringing together under the term of ether extract, a large class of bodies which were generally supposed to be fats, but we all know the digestibility of fats is much higher than the coefficient mentioned in the paper. And this leads me to say what has long been known, that the ether extracts contain a great deal besides fats, and especially are likely to be mixed with chlorophyl, or its alteration products. These products doubtless will soon be the subject also of investigation, so that we may be able to separate the so-called ether extracts into true fats and into other bodies which are much less digestible. Still we should not, I think, be misled by digestibility. Because a body disappears during its passage through the intestinal canal, is no positive proof of its assimilation. Starch, as you see, disappears almost completely, during its transit through the assimilated canal, but that is no positive proof that starch is absolutely eliminated, any more than some of the other foods, less easily changed than starch. This change begins in the mouth during mastication in the alkaline action of the saliva and is continued in a large extent in the stomach before the acidity of the stomach becomes too great. It is supposed that after the ingestion of food through the esophagus the contents of the stomach remain alkaline for some time, and the conversion of the starch goes forward with great rapidity, and is continued, perhaps, after the acidity of the stomach has been established. The digestive coefficients have value in estimating the nutritive value of food. But we do not want food that is all 
digested. If we were all put on a diet that is all digested, we would all die, because it is necessary for the purpose of digestion that the peristaltic action of the bowels be secured, and there must be something to excite this action. If you digest everything you eat you will derange the health and thwart the very purposes for which feeding is practiced. And hence these undigested bodies have a value, you may call it a negative value if you will, simply because they are not absorbed. Nevertheless, they have their uses in the animal economy. So the fact that a certain food product has a digestive coefficient of 100 , another of 80 , another of 60 , another of 30 , does not furnish stufficient data on which to base any correct idea of the actual value of those foods to the animal economy. They all have a value, not only a nutritive value, but a mechanical value, and this must not be lost sight of. In fact, the methods which we practice of valuing foods is faulty, whether we consider it from the view of the physiologist simply by the amount of it which is digested, or whether we consider it from the point of view of the chemist by the amount of heat which a food will give, or whether we view it simply from the light of the physician in regard to its general effect upon the system. That is, judging a food by any one of these three standards, we reach a false conclusion. They must all be combined in order to determine the true value of the food. In determining the value of these wheat carbohydrates as foods, we must look at them from the amount of heat that they will give, that is one of the functions of food; we must look at them from their coefficients of digestibility; and we must look at them, on the other hand, from the physician's or the hygienic point of view, from their effect upon the health. Now, if in valuing food we will keep these three points in mind, we will come to a very much better conclusion than if we insist upon judging it from a single standard. We know how apt we are to think that the particular thing we are doing is the only thing in the world which is worth doing, and that everybody must come to our standard of judging any particular thing, especially a food; but this is an erroneous idea.

From the analytical point of view, too, this paper is valuable. We are now beginning to reach a point where we can discriminate among these carbohydrates, not only in a qualitative, but 
also in a quantitative way. For many years the methods of so simple a determination as that of starch were very much mixed up, and in fact, it is rather difficult, even to-day, to estimate the actual quantity of starch which is present in a cereal with absolute accuracy. Of course, I do not mean with approximate accuracy. The old methods of digesting a cereal with an acid and then determining the sugar, we know to be very faulty, but the modern methods of separating the starch are, as indicated by the speaker, approximately correct. The solution of starch by diastase is one of the methods very largely practiced in our own laboratory. We also aid the solution by heating in an autoclave to a high temperature. We think we get a little better results this way than by the use of the malt extract alone. The specific rotatory power of soluble starch gives another basis for the determination, and a rapid determination of the starch present, but the method has not proved satisfactory. in our laboratory. After the starch is dissolved, then we can apply the acid and convert it into dextrose. By some one of these methods the starch can be separated, practically, from the other carbohydrates present in cereal grains. When we reach the bran we are at the very beginning of the word furfurol, which, I believe, is derived from the Latin words which mean "bran oil." The fact of the derivation of this substance from the wheat bran has been known for many years. For fifty or sixty years, perhaps, the fact has been known that wheat bran would yield furfural when digested with an acid, although it was not known at the time that furfural was the splitting-up product of a five-atom sugar former. That was a matter of later knowledge. This substance is an old one, and yet it comes to us now under new forms and in new lights. The most difficult part of the problem, as indicated by the speaker, was the final separation of the lignins and cellulose, and allied bodies, and perhaps there is a great deal to be done yet before we reach final results. These bodies are so near each other and run into each other by such almost imperceptible gradations that it requires the highest degree of analytical skill, as well as of chemical research and investigation, to devise means by which they can be practically separated from one another. Therefore I think this Society should welcome all investigations of this nature, and I hope it 
will not be long before this paper appears in full in the columns of the Journal.

Mr. M. L. Griffin: Mr. President and gentlemen, I have been very much interested in this paper presented this morning. It is in line with work which I have been connected with for some time, and as Mr. Stone and Dr. Wiley have said, any information on this subject is of great utility to this Society, to chemists, and to the chemical world. The difficulties of separating the bodies which have been referred to, are extreme, and any information, though incomplete, is certainly welcome.

We digest IIo cords of wood daily for paper-making at Mechanicville, N. Y., which illustrates how intimately the subject of this paper connects itself to the commercial world, not only in the digestion of carbohydrates by the animal economy but also to manufacturing industries. I venture to say that the commercial practice of separating cellulose from the intercellular and incrustating matter of wood or carbohydrates generally is very much ahead of the science of the subject.

The difficulty of making a laboratory separation of the components of wood or any carbohydrate resulting from plant growth lies in the fact that the more highly organized or developed molecules are a growth by continuous processes. If you will picture to your minds the growth of a tree from the coursing of the life-giving sap just under the bark where the latest growth is taking place to the heart of the tree. you will find a continuous development or growth with no clean cut gradations. This is the reason why it is so difficult to make definite separations within narrow limits.

Reagents which will dissolve incrusting and intercellular substances in wood are not without effect upon the cellulose itself.

This brings us to the methods laid down in books for the determination of cellulose in woody tissues. In brief they are summed up in alternate treatment of the samples over the waterbath, with an alkali and an oxidizing agent as chlorine or bromine. This is repeated until you get " pure cellulose."

You who have tried this, know how tedious it is and how worthless the results are, simply for the reasons given above. As technical chemists we know that a practical test for the 
determination of cellulose in woody tissues by using small digesters in which we may subject the material to high temperature and pressure with suitable chemicals for a short time, will make a much clearer separation of cellulose and with less destructive effect. This is the method I employ for technical purposes.

We also know that some chemicals are more destructive to the cellulose than others in this connection. A chemical treatment in which the materials are not allowed to oxidize during the process of digestion, has a much less destructive effect on the cellulose, and produces a much more durable fiber for paper-making. The importance of this increased "yield", as manufacturers call it, is very apparent. The completeness of the separation of the cellulose from all foreign matter is equally important and desirable from every point of riew.

I trust I have said nothing which will deter any chemist from undertaking work along this line. Our knowledge of the insoluble carbohydrates is very limited, and while we may only approximate the results we desire, there is a vast field here for highly valuable and useful service.

We may congratulate ourselves on the presentation of this paper by one of our members.

President Dudley: I would like to ask Mr. Sherman if the coefficient of digestibility of the whole wheat can be obtained from this paper?

Mr. Sherman: No, it was just an experiment on the bran. The digestibility of the whole sample was 68.33 per cent. In regard to Mr. Griffin's remarks on the analytical methods, and especially for cellulose, I think that we will have to design our methods largely, at least as yet, according to the object we have in view. As I indicated, I do not think that we can say that cellulose, the cellulose we get from any given fiber, will be $\mathrm{C}_{6} \mathrm{H}_{10} \mathrm{O}_{5}$, and nothing else; in fact I am quite sure we cannot say that. What I have attempted was the separation on chemical lines, as far as possible, and as I am very free to admit, I did not get any pure cellulose $\left(\mathrm{C}_{6} \mathrm{H}_{10} \mathrm{O}_{5}\right)$ by any of the methods, and the methods that gave the purest cellulose gave too low a yield. I think the chlorine method is much the best, because it attacks the lignin group selectively, and does not disintegrate the whole as the strong alkali usually does. This cellulose 
consists of both hexose anhydrides and pentose anhydrides; I am not prepared to say whether that would be suitable for paper-making or not; I should think likely not. So that what we arrive at when we try to work from a purely chemical standpoint might be entirely unsuited to a given commercial case.

\title{
IMPROVEMENTS ON DR. SQUIBB'S VOLUMETRIC METHOD FOR ESTIMATING ACETONE.
}

\author{
BY LYMAN F. KEHIER. \\ Received February 13, 1897 .
}

I $\mathrm{N}$ the December ${ }^{1}$ number of this Journal Dr. Squibb gave a a translation of MM. J. Robinea $\mathfrak{u}^{2}$ and G. Rollin's method for estimating acetone, as well as a modification of the process by himself. Both methods consist essentially in mixing an aqueous acetone solution with a strongly alkaline potassium iodide solution and converting the acetone into iodoform by means of a titrated solution of sodium hypochlorite, the end reaction being determined by means of a bicarbonated starch solution.

Dr. Squibb kindly sent me his modification last summer. Prior to that time I had used Messinger's process exclusively. I have not applied Robineau and Rollin's method to any extent, but have studied and worked with Dr. Squibb's modification of the same quite considerably.

The two latter methods will meet with two objections; first, a pure acetone, and second, the tedious, time-consuming drop end reaction. Pure acetone is not so readily prepared. I have not been able to secure acetone that assayed more than 99.73 per cent. of pure material, by either Messinger's ${ }^{3}$ process or the one presently to be described. This small quantity may have volatilized in course of the work, but the loss would be practically constant for all the methods; consequently, the basis of calculation would be 10o, when in reality it is less. Grant that absolutely pure acetone can be made, it is not readily secured when desired.

I have modified Dr. Squibb's method so that both the pure

1 This Journa1, 18, 1068; Ephemeris, 4, 1759 .

2 1893: Mon, Sci., (4), 7, Pt. I, 272.

8 1888: Ber. d. chem. Ges, $21,3366$. 